\title{
AN ANALYSIS OF DISCOVERY RULES
}

\author{
JOEL SOBEL* \\ I \\ INTRODUCTION
}

When bargainers have access to different information, they may find it impossible to reach agreements without costly impasses. Several people use this insight to build models in which asymmetrically informed litigants fail to settle disputes, choosing instead to pursue a costly trial in order to resolve a conflict. This article develops a model in which incomplete information between litigants leads to bargaining impasses; the model is then used to compare the properties of discovery rules that govern the pretrial disclosure of information.

In the model of this article, two potential litigants have private information regarding an accident. Should the dispute go to trial, this information determines the outcome. After the injured party decides to bring suit, the defendant can make an offer to settle out of court. If the plaintiff accepts the offer, the litigants settle. If the plaintiff rejects the offer, she may make a counteroffer. If the defendant rejects the plaintiff's counteroffer, the litigants go to trial. The model places no restrictions on what the litigants may offer. Hence, a litigant may learn about an opponent's private information from the amount of a settlement offer. The amount and probability of a settlement are endogenously determined (that is, derived from litigant's behavior and not predetermined). This article presents a framework in which to measure the effect of legal rules on the outcomes of the litigation process. Specifically, by explicitly modeling the informational asymmetries that lead to disagreements, I am able to study the effect on the nature and frequency of settlements of rules that require defendants to reveal private information. The analysis demonstrates that if disclosure is costly, then the defendant will not voluntarily disclose information; that mandatory discovery reduces the probability of trials, benefits plaintiffs, and harms defendants; and that the litigation process typically provides a biased sample of disputes for trial.

Copyright $(\mathcal{C} 1989$ by Law and Contemporary Problems

* Professor of Economics, University of California, San Diego.

The first version of this article appeared in the spring of 1985. I thank Stephen Bundy, Peter Dohlman, Lewis Kornhauser, Paul Milgrom, Dan Orr, Carol Price, Dan Rubinfeld, Alan Schwartz, and Dale Stahl for encouragement and/or comments. They are not to blame for this article's shortcomings. I am happy to acknowledge financial support from NSF and the Sloan Foundation. Law and Contemporary Problems Senior Editor William O'Neil and Staff Editor Garrett Epps are responsible for transforming a technical piece of applied game theory into the current article. Any legal professional who attempted to read an earlier version of this article will recognize the magnitude of their efforts and thank them. 
Other work in sequential litigation models has been unable to present a theoretical justification for selecting a single equilibrium outcome in a game in which litigants' actions convey information. For this reason, comparativestatics analysis ${ }^{1}$ based on examining a single equilibrium could not be convincing. I apply equilibrium-selection arguments of Banks and Sobel, and Kohlberg and Mertens to characterize a unique outcome in a game in which both litigants have private information and both may make settlement offers. ${ }^{2}$

While similar in structure to other game-theoretic treatments of settlement and litigation, my model differs from the others because it allows for multiple offers, information transmission via actions, and two-sided uncertainty in which both the plaintiff and defendant are uncertain about the extent of the other's negligence or injury, respectively. Bebchuk, Cave, P'ng, Reinganum and Wilde, and Salant present settlement models in which one litigant has private information. ${ }^{3}$ In Bebchuk's model, the defendant has private information, but only the plaintiff can make settlement offers. Bebchuk is able to characterize a unique equilibrium outcome. ${ }^{4}$ However, because only the uninformed litigant can make offers, the settlement process does not convey information. In the models of Cave, Reinganum and Wilde, and Salant, the informed plaintiff makes a settlement demand. These models are essentially identical. ${ }^{5}$ Reinganum and Wilde concentrate their analysis on one of a large number of sequential equilibria. ${ }^{6}$ The one-stage version of the game that I analyze, in which only the plaintiff makes settlement offers, reduces to the model of Salant. ${ }^{7}$ Moreover, the equilibrium that I select in the one-stage model corresponds to that analyzed by Reinganum and Wilde. ${ }^{8}$ My arguments lend some theoretical support to their analysis. Cave's paper discusses the implications of various equilibrium refinement ideas on the outcomes in this model. ${ }^{9}$ The informed defendant may decide to make a

1. Comparative statics is a method of analysis that compares a new equilibrium position with an old one following a disturbance to the system (e.g., changing an exogenous variable).

2. Banks \& Sobel, Equilibrium Selection in Signaling Games, 55 Econometrica 647 (1987); Kohlberg \& Mertens, On the Strategic Stability of Equilibria, 54 Econometrica 1003 (1986).

3. Bebchuk, Litigation and Settlement Under Imperfect Information, 15 RAND J. EcoN. 404, 406 (1984); P'ng, Strategic Behavior in Suit, Settlement, and Trial, 14 BELL J. ECON. 539 (1983); Reinganum \& Wilde, Settlement, Litigation and the Allocation of Litigation Costs, 17 RAND J. Econ. 557, 559 (1986); Cave, Refinements of Sequential Equilibrium in a Legal Settlements Game, (rev. ed. Mar. 1987) (Rand Corporation working paper); Salant, Litigation of Settlement Demands Questioned by Bayesian Defendants, Social Science Working Paper 516, Division of the Humanities and Social Sciences, California Institute of Technology (1984).

4. Bebchuck, supra note 3, at 407-08.

5. Cave, supra note 3, at 6; Reinganum \& Wilde, supra note 3, at 557; Salant, supra note 3, at 4.

6. Reinganum \& Wilde, supra note 3 , at 560. A sequential equilibrium is a collection of strategies (one for each player), and beliefs (describing what a player believes about his opponents whenever it is his turn to move). A sequential equilibrium is a Nash Equilibrium, see infra note 10. Each player's strategy must maximize his expected payoff given his beliefs and the strategies of the other players. The beliefs about what other players do must be consistent with prior information and equilibrium strategies, see infra note 27. See Kreps \& Wilson, Sequential Equilibria, 50 EconomETrica 863 (1982).

7. Salant, supra note 3 , at 7 .

8. Reinganum \& Wilde, supra note 3 .

9. Cave, supra note 3, at 2-6. 
settlement offer in P'ng's model. However, the amount of this offer is determined exogenously. P'ng also does not distinguish between sequential equilibria and Nash Equilibria ${ }^{10}$ that depend on a plaintiff's (incredible) commitment to go to trial." Banks analyzes a model with two-sided uncertainty and the possibility of information transmission. He restricts attention to a subset of the sequential equilibria and analyzes the effect of various liability rules on the outcome of the litigation process. ${ }^{12}$ P'ng examines the influence legal rule changes have on decisions to take care prior to litigation. ${ }^{13}$ Cho and Schweizer look at the sets of equilibria that survive various refinement arguments in models with two-sided incomplete information. ${ }^{14}$ Meurer's strategic settlement model differs from the others discussed because a settlement in Meurer's model may be an agreement that allows two firms to share monopoly profits (a patent license agreement). ${ }^{15}$

I know of three other game-theoretic models of the settlement process. Ordover and Rubinstein model a game in which two parties have a fixed, finite number of opportunities to reach an agreement. During this time, if one party concedes, a settlement occurs at an exogenously determined value. Otherwise, a trial ensues. One party knows the outcome that would result at a trial, whereas the other party does not. The uninformed party can draw inferences about his opponent's information when the opponent fails to concede. However, there is no way to convey information through settlement offers. ${ }^{16}$ Cooter, Marks, Mnookin, and Samuelson analyze models in which both sides have private information and the potential litigants make simultaneous settlement offers. If the offers are compatible (that is, the defendant offers to pay at least as much as the plaintiff demands), then the litigants compromise; otherwise, they go to trial. Cooter, Marks, and Mnookin present comparative-statics results, but they do not explicitly

10. A player's strategy describes a complete plan of action. In the model of pretrial bargaining a strategy for the plaintiff specifies as a function of her private information, which settlements of the defendant to accept and which to reject, and, in the event of a rejection, what counteroffer to make. A strategy combination is a set consisting of one strategy for each player in the game.

A Nash Equilibrium is a strategy combination such that no player has an incentive to change his or her strategy (that is, that doing so would not raise the expected payoff) as long as the other players do not deviate from their strategies. In order to obtain predictions, I make further restrictions (or refinements) on the Nash Equilibrium concept, see infra note 23.

11. P'ng, supra note 3 .

12. Banks, Negligence, Liability, and the Settlement of Disputes (1986) (doctoral dissertation, California Institute of Technology).

13. P'ng, Liability, Litigation, and Incentives for Care, 34 J. Pub. Econ. 61 (1987).

14. I. Cho, Pre-Trial Negotiation Under Asymmetric Negotiation, in Refinement of Sequential Equilibrium: Theory and Application (1986) (doctoral dissertation, Princeton University); see also Schweizer, Litigation and Settlement under Two-sided Incomplete Information, 56 REv. Econ. STUD. 163 (1989).

15. Meurer, The Settlement of Patent Litigation, 20 Rand J. ECON. 77 (1989).

16. Ordover \& Rubinstein, A Sequential Concession Game with Asymmetric Information, 101 Q.J. EcoN. 879 (1986). 
describe their equilibria, and the nature of the informational asymmetries in their model is unclear. ${ }^{17}$

Spulber characterizes the incentive-efficient mechanisms ${ }^{18}$ for a class of settlement problems. This approach promises to provide a description of outcomes that is independent of a particular extensive-form description of the settlement game. Spulber's comparative-statics results describe the changes in the set of incentive-efficient outcomes. ${ }^{19}$

Gould studies a model that predicts which disputes will be settled prior to going to court. Settlements are not possible in this case if litigants have different estimates about whether they will prevail at a trial. Gould does not explain how these differences of opinion arise. ${ }^{20}$ Posner also discusses factors that encourage settlement prior to a trial. He identifies a simple cost-benefit tradeoff that determines when disputes will go to court. ${ }^{21}$ Shavell models the decision to bring a suit as a decision problem faced by the plaintiff alone. $\mathrm{He}$ studies how the rule that governs the allocation of costs in the event of a trial influences the pattern of settlements. ${ }^{22}$ All three of these models ignore the possibility that one litigant's behavior may influence the other's subjective assessment of the outcome in the event of a trial. Game-theoretic models focus precisely on this strategic aspect of the pretrial bargaining process.

I wish to emphasize three aspects of this article. The first aspect is methodological. It is possible to provide a general solution concept ${ }^{23}$ that selects a unique outcome for a strategic model of pretrial bargaining. These techniques make it possible to analyze a broad set of models related to law and economics. However, the construction of equilibria and proofs of uniqueness are routine technical exercises; the Appendix contains an outline of these arguments.

Second, it is important to emphasize that most of the qualitative results of this article depend strongly on the model itself and the solution concept I use. While the uniqueness results that I obtain are not special to the particular game that I describe, the characteristics of the outcome are. The legal bargaining process is a complicated one. In order to develop tractable

17. Cooter, Marks \& Mnookin, Bargaining in the Shadow of the Law: A Testable Model of Strategic Behavior, $11 \mathrm{~J}$. LeGAL STUd. 225, 230 (1982). Samuelson, Negotiation vs. Litigation, Boston University School of Management Working Paper (rev. ed. 1983).

18. Incentive-efficient mechanisms are mechanisms that lead to efficient outcomes (the best allocation of resources), given the constraints imposed on information or actions.

19. Spulber, Negligence, Contributory Negligence and Pre-Trial Settlement Negotiation, Modeling Research Group Working Paper No. M8511, Department of Economics, University of California, San Diego (1985).

20. Gould, The Economics of Legal Conflicts, 2 J. LEGAL STUd. 279, 284 (1973).

21. Posner, An Economic Approach to Legal Procedure and Judicial Administration, 2 J. Legal Stud. 399,418 (1973).

22. Shavell, Suit and Settlement and Trial: A Theoretical Analysis Under Alternative Methods for the Allocation of Legal Costs, $11 \mathrm{~J}$. Legal STUD. 55 (1988).

23. A solution concept is simply an equilibrium concept like the sequential equilibrium, supra note 6, or the Nash Equilibrium, supra note 10. By a general solution concept, I mean a solution concept that applies to a broad class of games rather than to a particular example. In this article, I use the DI refinement of the sequential equilibrium concept developed by Cho and Kreps. See infra note 30 . 
models, one must omit certain details and concentrate on others. I do not apologize for neglecting the impact of litigation on third parties (either through reputation effects or because the discovery process reveals valuable information to third parties); the bargaining process is rich and interesting enough without including this feature. However, many conclusions obtained from my model (and other game-theoretic models of the settlement process) depend on idealized details of the bargaining process. For example, the number of rounds of bargaining prior to trial and, especially, the party who has the last word, dramatically influence the impact of rules that govern allocation of court costs. This type of sensitivity results from a genuine indeterminacy in the bargaining process. In order to be confident about the predictions from game models, one must include more institutional detail. The analysis of this paper only demonstrates the range of possible qualitative results.

Third, some conclusions from the strategic model of settlement and litigation appear to be general. Pretrial settlements occur because disagreement is costly. If there were no costs associated with trial, one would not expect serious pretrial bargaining. One cannot depend upon voluntary disclosure to reveal all relevant information prior to trial. The rules governing discovery and pretrial bargaining influence the type of dispute that goes to trial. However, one cannot make general statements about the nature of all disputes from the nature of disputes that actually lead to trial.

II

\section{The MOdeL}

This section describes the basic model.

Players. There are two players (litigants): a plaintiff $(P)$ and a defendant $(d)$. Note that throughout this article, upper-case variables refer to the plaintiff and lower-case variables refer to the defendant.

Information. Both the plaintiff and the defendant begin the game with private information that reflects the quality of their case. $P$ 's information could reflect the amount of damage $P$ suffered; $d$ 's information could reflect his own degree of negligence. The information is private: Neither player's information is known to the other player. I assume that a litigant's information can take on one of two possible values, low ( $L$ or $l$ ) or high $(H$ or $h$ ). I call a plaintiff who has (observes) private information $i$, a plaintiff of type $i$ or $P-i$, where $i=L$ for a low injury or $H$ for a serious injury. Similarly, $d-j$ is a defendant who has (observes) private information $j$, where $j=l$ for a weak case (high negligence) or $h$ for a strong case (low negligence). The probability before any action has taken place (prior probability), that $d$ is type $j$ is $q_{j}$; the prior probability that $P$ is type $i$ is $Q_{j}$. So, for example, the prior probability that $d$ is type $l$ might be $q_{l}=50$ percent. This belief, of course, may change once bargaining has begun, since information about types is conveyed through actions; such a revised belief would be called a posterior belief. I assume that one litigant's type has no effect in determining the other 
litigant's type: that is, that $q_{j}$ does not depend on $P$ 's type $i$ and that $Q_{i}$ does not depend on $d$ 's type $j$. This independence assumption is not restrictive; that is, such a dependence could be included in this model without changing any results.

Litigation Process. The litigation process takes place in stages. First, the plaintiff decides to sue. Second, the defendant makes a settlement offer to the plaintiff. If the plaintiff accepts the offer, the litigation process stops, and the defendant pays the plaintiff the amount of the offer. If the plaintiff rejects the offer, negotiation continues. What happens next depends on the nature of the discovery process. I explicitly consider two discovery rules. Under mandatory disclosure, the defendant must reveal his private information if $P$ rejects his first offer. Misrepresentation is not possible. Therefore, after $d$ reveals $j, P$ knows $d$ 's type. I assume that the cost of disclosure is $c>0$, regardless of $d$ 's type. When the other discovery rule holds, $d$ does not disclose $j$. I informally discuss a third possibility, voluntary disclosure, and argue that the two polar cases capture the properties of a voluntary-disclosure model. After the discovery phase, $P$ makes a settlement demand. If $d$ accepts this demand, the litigation process stops, and the defendant pays the plaintiff the amount $P$ demanded. If $d$ rejects the demand, the dispute goes to trial. At a trial, $P$ and $d$ receive payoffs that depend on their private information. Implicitly I assume that the judge and jury learn about the private information of the litigants during trial and form their verdict accordingly.

Payoffs. Litigants are risk-neutral (that is, they would not require a higher expected return as compensation for an increase in risk). If they fail to settle their dispute out of court, the court determines the payoffs. When $P$ observes $i$, and $d$ observes $j$ (where again $i$ and $j$ can take on high or low values), $T(i, j)$ denotes what $P$ expects to receive (expected payoff), net of court costs, if the case goes to trial, and $t(i, j)$ denotes the amount that $d$ expects to pay (including court costs). I assume that

$$
\begin{aligned}
& \text { (1) } T(L, h)<T(L, l), \\
& \text { (2) } T(H, h)<T(H, l), \\
& \text { (3) } t(L, h)<t(L, l) \text {, and } \\
& \text { (4) } t(H, h)<t(H, l) .
\end{aligned}
$$

The first inequality states that $P$ 's expected payoff when her damages are low and the defendant's case is strong will be less than her expected payoff when her damages are high and the defendant's case is weak. The other inequalities can be described in a similar fashion.

Because $P$ will get a larger payoff at the trial if $i=H$, she prefers that $i=H$ rather than $i=L$, independent of $j$; likewise $P$ prefers that $j=l$ rather than $j=h$ independent of $i$. The defendant's preferences go in the opposite direction (recall that $t(i, j)$ is $d-j$ 's payment given that $P$ is type $i$ ). I also assume that

$$
0<\mathrm{T}(i, j)<t(i, j) \text {. }
$$

The first inequality $(0<T(i, j))$ states that $P$ always has something to gain by going to trial. In Part IV, I discuss what happens when this condition fails to hold. The second inequality $(T(i, j)<t(i, j))$ implies that when there is a trial, 
the defendant pays more than the amount $P$ receives. This assumption captures the idea of court costs. The total amount of these costs is $t(i, j)-T(i, j)$. While it would be easy to present a specification that describes how these costs are allocated, I argue later that the game that I analyze is too special to give meaningful answers to questions about the effect of rules governing the allocation of court costs. The only costs in the negotiation process are disclosure costs and court costs. ${ }^{24}$

Strategies. The strategies ${ }^{25}$ for $P$ consist of probabilities $R_{i}(s)$ and demands $S_{i}$. The probability that $P-i$ accepts $d$ 's settlement offer of $s$ is $R_{i}(s)$. $S_{i}$ is $P-i$ 's settlement demand given that she has not accepted $d$ 's first offer. The first offer of $d,(s)$, and subsequent disclosure of his private information (if required) typically conveyed information to $P$. Therefore, $S_{i}$ depends on $s$ and $d$ 's disclosure (if any). The strategies for $d$ consist of probabilities $r_{j}(S)$ and offer $s_{j}$. The definition of $r_{j}(S)$ is the probability that $d-j$ accepts a settlement demand $S$ given that $P$ rejects $d$ 's offer. The definition of $s_{j}$ is $d-j$ 's settlement offer. To give an example, if $i=L$ and $j=h$, then $d-h$ would offer $s_{h}$, which $P$ would accept with a probability of $R_{i}\left(s_{h}\right)$. If $s_{h}$ was rejected, $P-L$ would make a settlement demand of $S_{L}$, which $d-h$ would accept with a probability of $r_{h}\left(S_{L}\right) \cdot{ }^{26}$

Beliefs. In order to describe equilibria, I need to specify how litigants interpret offers that they do not expect to receive in equilibrium. The beliefs of $d$ are probability distributions for each $S$ and $s,(\mu(L \mid S, s), \mu(H \mid S, s))$, where $\mu(i \mid S, s)$ is the probability that $d$ believes $P$ is type $i$ given the demand $S$ and offer $s$. Similarly, $v(j \mid s)$ is the probability that $P$ assigns to the event that $d$ is type $j$ following an offer $s$. Beliefs are held by each player about the other player's type. These beliefs evolve during the course of bargaining, as more information is made available, via the actions of the other player. For example, $d-l$ might initially believe that $P$ is type $H$ with a probability of 50 percent $\left(Q_{H}=50\right.$ percent). After $d$ makes an offer of $s$ and (if $s$ is rejected) receives a settlement demand of $S$ (both the rejection and the counterdemand

24. Total court costs given $i$ and $j$ are equal to $t(i, j)-T(i, j)$. Therefore, I can evaluate a rule that allocates court costs as a function of $i$ and $j$ by looking at how equilibria vary when $t$ and $T$ change but $t-T$ remains constant. I can also derive the values $t$ and $T$ by assuming that $i$ and $j$ jointly determine the probability that the plaintiff wins a trial. Specifically, if $p(i, j)$ is the probability that $P$ wins given $i$ and $j, M$ is the amount that $P$ wins, and $P$ 's $\left(d\right.$ 's) court costs are $B_{i}\left(b_{i}\right)$, then

$$
\begin{gathered}
t(i, j)=p(i, j) M+b_{i j} \text { and } \\
T(i, j)=p(i, j) M-B_{i j}
\end{gathered}
$$

Varying the $b_{i}$ and $B_{i}$ allows me to describe all of the standard methods of allocating court costs.

25. See supra note 10 .

26. It is also possible to allow litigants to use probabilistic settlement offers. Such a mixed strategy would involve a player making more than one offer with positive probability. If the defendant made a probabilistic settlement offer, then his mixed strategy would specify the probability that his counteroffer is $s$ for any value of $s$. For example, the defendant may decide to be aggressive one-half of the time and only offer to pay the plaintiff a token amount to avoid a trial, while the rest of the time making a more generous settlement offer. This type of mixed strategy does not arise in the equilibria that I characterize. The reason for this is that the defendant will always find a single offer to be superior than all others: When it is a good strategy to be aggressive, it will necessarily be a poor strategy to be conciliatory. Therefore there is no loss of generality in ignoring the possibility of using these general strategies in the description of the game. 
convey information about $P$ ), he might then believe that $P$ is type $H$ with a probability of 40 percent. The important point here is that beliefs allow a player to interpret and respond in an intelligent way even to unexpected offers or demands.

Equilibrium. An equilibrium consists of strategies and beliefs $\left(R_{i}(s), S_{i}, r_{j}(S)\right.$, $\left.s_{j} ; \boldsymbol{\mu}(i \mid S, s), v(j \mid s)\right)$ for $i, j=0,1$ such that, given the strategies of the other player and beliefs, a player's strategy choice maximizes his or her expected payoff. I require in the model that a player's beliefs satisfy additional requirements. The beliefs must support a sequential equilibrium. ${ }^{27}$. The notion of sequential equilibria, due to Kreps and Wilson, captures the idea that players should respond optimally to some consistent assessment of how the game has been played. In other words, each player observes the other player's actions and can infer the probability of an event (or type). He or she will then respond in a way that maximizes his or her expected payoff. ${ }^{28}$

The concept of sequential equilibrium does not place sufficient restrictions on the way in which unexpected offers and demands are interpreted. Recent theoretical papers by Banks and Sobel, ${ }^{29}$ Cho and Kreps, ${ }^{30}$ and Cho and Sobel $^{31}$ have exploited ideas of Kohlberg and Mertens ${ }^{32}$ to refine the sequential equilibrium concept. The refinement ideas use the notion of equilibrium dominance. ${ }^{33}$ Imagine that the litigants are familiar with the way that settlement games have been played in the past. Imagine that both plaintiff and defendant know clearly what to expect if they use their information in the "expected" way (that is, they follow equilibrium strategies). How should they decide whether to make an "unexpected" offer? One approach is to compute the expected gain from making an unexpected offer and to compare this gain to the equilibrium utility.

The refinement notion, or restriction, that this article employs assumes that unexpected offers come from the type of agent more likely to gain from making them. Concretely, if both types of plaintiff are expected to make the same settlement demand in equilibrium, then I require that a higher (out-ofequilibrium) demand be interpreted as coming from the more injured plaintiff

27. Beliefs support a sequential equilibrium if they are consistent with prior distributions and equilibrium strategies. In this model, Bayes' Rule determines $v(j \mid s)$ whenever the equilibrium specifies that $d$ makes the offer $s$ with positive probability and Bayes' Rule determines $\mu\left(i \mid S_{,} s\right)$ whenever the equilibrium specifies that $d$ makes the offer $s$ and, with positive probability, $P$ responds to this offer with the demand $S$. Bayes' Rule is the method by which new information (the result of an experiment or, in this model, a settlement offer) is combined with a given distribution (the prior) to form a new distribution (the posterior). See 1 Feller, An Introduction to Probability Theory and Its Applications 124 (3d ed. 1968).

28. Kreps \& Wilson, supra note 6 .

29. Banks \& Sobel, supra note 2.

30. Cho \& Kreps, Signaling Games and Stable Equilibria, 102 Q.J. Econ. 179 (1987).

31. Cho \& Sobel, Strategic Stability and Uniqueness in Signaling Games, Discussion Paper No. 87-10, Department of Economics, University of California, San Diego (1987).

32. Kohlberg \& Mertens, supra note 2.

33. Equilibrium dominance is an argument used to eliminate equilibria that involve implausible behavior. When equilibrium dominance arguments are applied, beliefs are not allowed to place positive probability on the possibility that a player would use a strategy that leads to a payoff strictly less than an equilibrium payoff. 
with a probability of 100 percent. This result follows because the more injured plaintiff has more to lose from increasing the demand than the less injured plaintiff, because the less injured plaintiff gains more in court when there is no settlement. Cho and Kreps call this restriction the Dl criterion. ${ }^{34}$ I define the restriction formally in the Appendix. To follow the article, one need only note that the restriction requires that players interpret demands higher (lower) than the equilibrium specifies for the more injured plaintiff as signs that the plaintiff is more (less) injured, and offers higher (lower) than the equilibrium specifies for the strong defendant as signs that the defendant has a strong (weak) case. Notice that these inferences necessarily are drawn for offers and demands actually specified by equilibrium strategies. That is, in any Nash Equilibrium to the game, the less injured type of plaintiff never demands more than the more injured type of plaintiff. It is important to emphasize that restricting beliefs reduces the size of the equilibrium set by limiting the range of off-the-equilibrium-path behavior. The restrictions derived from $\mathrm{D} 1$ are strong, but they are plausible, and they are consistent with existence of equilibrium in general games. This type of restriction is necessary if one wishes to obtain a unique equilibrium prediction for the game analyzed in this article. Below, I refer to the unique equilibrium, under the more restrictive D1 criterion, as the unique D1 outcome. ${ }^{35}$

III

The One-Stage Model

This Part describes the equilibrium behavior in a settlement model in which only one round of bargaining can take place before trial. I assume that the plaintiff makes a single demand $S$, which the defendant either accepts or rejects. If the defendant accepts the demand, then $d$ pays $S$ to $P$. If the defendant rejects the demand, then the suit goes to trial. The expected judgment depends directly on the litigants' private information; given $i$ and $j$, $T(i, j)$ is the expected payment (net of court costs) to $P$ and $t(i, j)$ is $d$ 's expected payment.

I compute the equilibrium outcome of this game under two informational assumptions. First, I assume that $P$ knows $d$ 's type (that is, the value of $j$ ). This corresponds to the case in which there are liberal discovery rules that require $d$ to disclose private information. Next, I analyze the game that results if disclosure is not mandatory.

\section{A. Plaintiff Knows $d$ 's Type}

First, I describe a particular sequential equilibrium. Next, I demonstrate that this is the unique Dl outcome.

34. Cho \& Kreps, supra note 30, at 204.

35. I call an equilibrium unique if all equilibrium strategies agree along the equilibrium path. Strategies and beliefs may differ off the equilibrium path. 
To construct the equilibrium, first identify the demand that $P-L$ would make if his type were known to $d$. This demand must be $t(L, j)$ since this is what a type $\mathrm{j}$ defendant would pay if the case goes to trial. Therefore, it is a dominant strategy ${ }^{36}$ for $d-j$ to accept any demand $S<t(\mathrm{~L}, j)$. Further, if $d-j$ believes the demand $S>t(L, j)$ comes from $P-L$, then he rejects the demand. Thus, $P-L$ demands $t(L, j)$ which would be her demand in a oneperiod, complete information game with $d-j$.

I construct the equilibrium offer of $P-H, S_{H}(j)$, and $d$ 's response to it, to satisfy

(a) $\quad d-j$ infers that $i=H$ given $S_{H}(j)$,

(b) $P-L$ is indifferent between demanding $t(L, j)$ and $S_{H}(j)$, and

(c) $\quad P-H$ prefers to demand $S_{H}(j)$

$$
\text { to } t(L, j) \text {. }
$$

The first thing we can infer from conditions (a)-(c) is that $S_{H}(j)>t(L, j)$. Since $P-H$ has a stronger case than $P-L$, it makes sense that $P-H$ 's settlement demand will be higher than what $P-L$ can get should the case go to trial. Second, $d-j$ must reject the settlement demand $S_{H}(j)$ with a positive probability (otherwise $P-L$ would always demand $S_{H}(j)$ ). $d-j$ must accept $S_{H}(j)$ with some positive probability, since in (b) $P-L$ is indifferent between demanding $t(L, j)$ and $S_{H}(j)$, but if $S_{H}(j)$ were always rejected, then making this demand would yield $P-L T(L, j)<t(L, j)$. Third, we know that $S_{H}(j)=t(H, j)$ because $t(H, j)$ is the unique demand that makes $d-j$ indifferent between accepting or rejecting a demand given that $i=H ; d-j$ would always reject $S_{H}(j)>t(H, j)$ since this is more than he would have to pay in a trial. Likewise, $P-H$ would not demand less than $t(H, j)$ since she knows $d-j$ will have to pay this amount if the case goes to trial.

Assume now that $r^{*}$ equals the probability that $d-j$ accepts $t(H, j)$ (and $1-r^{*}$ is the probability of rejection). Then $P-L$ 's expected utility ${ }^{37}$ from $t(H, j)$ is $r^{*} t(H, j)+\left(1-r^{*}\right) T(L, j)$ since $P-L$ only gets $T(L, j)$ if $d-j$ rejects his demand of $S_{H}(j)=t(H, j)$. Recall from condition (b) that $P-L$ is indifferent between demanding $t(L, j)$ and $S_{H}(j)$. Then it must be the case that

$$
r^{*} t(H, j)+\left(1-r^{*}\right) T(L, j)=t(L, j) .
$$

We can rewrite this to solve for $r^{*}$, the probability of acceptance:

$$
r^{*}=[t(L, j)-T(L, j)] /[t(H, j)-T(L, j)]
$$

For $r^{*}$ defined in (1), we see that $P-H$ strictly prefers to make the demand $t(H, j)$ than to make the demand $t(L, j)$.

We have now described how $d$ and $P$ make their choices, based on the information revealing actions and expected demands of the other litigant. To

36. A dominant strategy is a strategy that maximizes a player's payoff given the strategies of the other players, no matter what the other players choose to do. Notice that the player's payoff might depend on the actions that other players take, but he or she will always obtain the highest possible payoff by playing a dominant strategy.

37. Utility is a numerical measure of an individual's preferences. An individual maximizes his utility by finding his most preferred bundle of goods, given his budget constraint. In the case described in this article, the plaintiff derives utility from money payoffs, since such payoffs increase her ability to purchase goods. The defendant's payments lower his utility. 
complete the description of the equilibrium, I must specify $d$ 's beliefs and responses for unexpected demands. For demands strictly between $t(L, j)$ and $t(H, j)$, the equilibrium concept that I employ requires that $d-j$ believe that $i=L$ with probability of 100 percent. Therefore, $d-j$ rejects these demands with probability of 100 percent. Independent of his beliefs, $d-j$ always rejects demands greater than $t(H, j)$ and always accepts demands less than $t(L, j)$. Any specification of beliefs given these demands supports an equilibrium.

Thus far, I have shown only that the strategies described above meet the requirements of a sequential equilibrium. In the appendix, I confirm that these strategies are indeed the only strategies that survive D1. A few remarks about the outcome are in order.

Remark 1. The equilibrium corresponds to the Pareto-dominating separating equilibrium that is often prominent in analyses of signaling models. ${ }^{38}$ In this kind of equilibrium, different types of a player use different strategies, thereby revealing their information. The "lowest" type (here $P-L$ ) does exactly as well as it would in a game with complete information. All higher types do less well, since they get their offer of $S_{H}(j)$ rejected with a positive probability, and thus cannot capture the full amount of court costs (that is, expected payoff will be less than $t(H, j))$.

Remark 2. The arguments I use to describe the equilibrium in which $P$ has exactly two types generalize to models in which $i$ can take on more than two values provided that $t(i, j)$ and $T(i, j)$ strictly increase when $i$ increases and $j$ is fixed $j$. When there is a continuum of types, this equilibrium corresponds to the separating equilibrium that Reinganum and Wilde analyze. ${ }^{39}$

Remark 3. The equilibrium requires that $d-j$ play a weakly dominated strategy $\mathrm{y}^{40}$ in response to the demand $t(H, j): d-j$ is indifferent between accepting and rejecting $t(H, j)$ when $i=H$; however, when $i=L$, he strictly prefers to reject $t(H, j)$. Many equilibrium refinement notions require that players do not use weakly dominated strategies in equilibrium. These notions apply to games in which the strategy spaces of the players are finite. When a player, such as $P$, can make a continuum of possible demands, a weakly dominated strategy is used. If I required that $P$ could only make demands that belong to a discrete set, $\Sigma$, the qualitative nature of the equilibrium would change little, but $P$ would no longer choose a weakly dominated strategy. Provided that $\Sigma$ has enough strategies to allow a separating equilibrium to exist, the unique Dl-equilibrium outcome would have

$$
S_{\mathrm{L}}(\mathrm{j})=\max \{S: S \in \Sigma, S \leqslant \mathrm{t}(\mathrm{L}, \mathrm{j})\}
$$

and

$$
\mathrm{S}_{\mathrm{H}}(\mathrm{j})=\max \{\mathrm{S}: \mathrm{S} \in \Sigma, \mathrm{S}<\mathrm{t}(\mathrm{H}, \mathrm{j})\}
$$

38. See Cho \& Sobel, supra note 31 , at 21 .

39. Reinganum \& Wilde, supra note 3.

40. See infra Table 1. The strategy that leads to acceptance of $P$ 's settlement demand (without knowing the value of $i$ ) is weakly dominated by a strategy that leads to rejection, since the payoff (with either strategy) is as good $(-S)$ when $i=H$, but worse when $i=L(-S>-t(L, j))$. 
$P-L$ would be indifferent between the demands $S_{L}(j)$ and $S_{H}(j)$ and would randomize between these two demands in order to make $d-j$ indifferent between accepting and rejecting $S_{H}(j), P-H$ would strictly prefer the demand $S_{H}(j)$ to $S_{L}(j) . d-j$ would accept $S_{L}(j)$ with a probability of 100 percent and reject $S_{H}(j)$ with exactly the probability needed to make $P-L$ indifferent between demanding $S_{L}(j)$ and $S_{H}(j)$. It is a simple matter to check that if $t(H, j) S_{H}(j)$ approaches zero, the probability that $P-L$ demands $S_{H}(j)$ goes to zero as well. The equilibrium that $I$ have constructed is a limit of equilibria to discrete games.

Observe that very simple games with continuous strategy spaces require players to use dominated strategies. For example, if two players bid for $\$ 1$, with the dollar going to the higher bidder at his bid and the lower bidder paying nothing (if the two bids are equal, then each player has a 50 percent probability of receiving the dollar and paying his bid), then the unique Nash Equilibrium requires that both players bid $\$ 1$ even though that strategy is weakly dominated.

Remark 4. The use of weakly dominated strategies in the equilibrium to the litigation game provides a clue to the difference between my model and the standard labor-market signaling model. ${ }^{41}$ In the labor-market signaling model, weakly dominated strategies are not used in equilibrium even when workers have available a continuum of signals (education levels). However, in standard signaling models it is always possible for a worker to invest so much in education that it never pays a lower-ability worker to imitate. In the litigation model, if $P-H$ 's demand is always accepted, then $P-L$ will want to imitate this demand. To separate the two types of plaintiffs the higher demand must be rejected with positive probability. To make this point a bit more generally, in the labor-market signaling model, workers must pay the cost of signaling whatever the response to the signal, whereas in my model, the plaintiff pays the cost of making a higher demand only if $d$ sometimes rejects that demand.

\section{B. Plaintiff Does Not Know $d$ 's Type}

If $d$ does not disclose the value of $j$, then $P$ acts as if $q_{j}$ is the probability that the defendant's type is $j$. The analysis corresponds to the case in which discovery is impossible. There is an intermediate case in which $d$ may voluntarily disclose his information. I point out below that if disclosure is costly, then it is an equilibrium for $d$ never to reveal his type to $P$. Therefore, this analysis pertains to the voluntary disclosure case.

Except for rare parameter values, there is a unique Dl outcome. The equilibrium is qualitatively similar to the equilibrium in the full disclosure model discussed above. The plaintiff makes fully revealing offers in which

41. Signaling is a way for a player to communicate his type when players are heterogeneous and asymmetrically informed. For example, in the standard labor-market signaling model, it is assumed that higher levels of education do not increase a worker's ability, but are less expensive to attain for higher ability workers. Therefore, employers may use educational levels to signal underlying ability. 
$P-L$ does exactly what she would do if $d$ knew that $i=L$, and $P-H$ makes a demand that leaves one type of $d$ indifferent between accepting the demand and going to trial given that $i=H$. The analysis is a bit more tedious than the earlier case because, depending on parameter values (that is, $q_{j}$ ), $P-i$ makes demands that only $d-l$ accepts (strong demands) or that both $d-l$ and $d-h$ accept (weak demands). However, the analysis of these cases is straightforward.

Table 1 shows the equilibrium strategies and payoffs for the games discussed in this section when $t(L, l)=t, t(H, l)=t+G, T(L, h)=t-G, t(H, h)=t$, and $t(i, j)-T(i, j)=K$. This is a representative special case in which the cost of trial is $K$ and the value of "good" information is $G$. For example, the difference in payoffs between $t(H, h)$ and $t(L, h)$ is $t-(t-G)=G$. While these assumptions are special, making them destroys no essential qualitative feature of equilibrium.

There are four different types of equilibrium. In Case A, $q_{t}$, the probabilty that the defendant is type $l$, is very high. $P-L$ makes a strong demand, which is accepted by $d-l$ but not by $d-h$. This case arises when $P-L$ prefers to risk a positive probability of a trial rather than make a demand acceptable to both types of defendant. Intuitively, this is a good strategy, since the probability that the defendant is type $l$ is high. In Case A, $P-H$ always prefers to make a strong demand, $t+\mathrm{G}$. This result holds whenever $P-L$ is indifferent between demanding $S_{L}$ and $S_{H}$. When $P-L$ is indifferent between $P-H$ 's demand and his own, $P-H$ 's equilibrium expected utility can be written

$$
U(L)+(1-r) G
$$

where $U(L)$ is $P-L$ 's equilibrium expected utility and $r$ is the probability that $d$ accepts the strong demand that $P-H$ makes in equilibrium. That is, the equilibrium utilities of $P-H$ and $P-L$ differ by $G=T(H, j)-\mathrm{T}(L, j)$ times the probability that $d$ rejects $P-H$ 's offer. Consequently, $P-H$ makes strong demands in these situations in order to maximize the difference in utility between her and $P-L$. If the defendant was certain to reject a strong demand in equilibrium (that is, $r$ is close to zero, the difference between $P-H$ 's and $P-L$ 's expected utility would be close to $G) .^{42}$

42. An example in Case A: Case A, with $q_{o} \geqslant K / k+g$ indicates the highest probability (relative to the three other Cases $\mathrm{B}$ through $\mathrm{D}$ ) that $d$ is type $d-0$. Take the situation where $i=L$. Although $P$ does not know $d$ 's type, it stands to reason that $P-L$ would make a strong demand, $t$, since $q_{l}$ is low. The defendant with a weak case, $d-0$, will accept this offer with $100 \%$ probability, since he cannot do any better (or worse) by going to trial. The $d-h$-type defendant can do better than $t$ by going to trial ( $d-h$ only pays $t-G$ in a trial) and thus accepts this demand with zero probability.

If $j=1$, then expected utility (payoffs) for $P-L$ and $d-l$ are calculated as follows. We know that $d-l$ accepts demand $t$ with $100 \%$ probability. Recall, however, that $P-L$ is indifferent between demanding a lower amount $S_{L}(=t)$ and copying $P-H$ 's high demand amount (under Case A) of $S_{1 /}(=t+G)$. To show this, note that $d-1$ accepts $S_{\| \prime}$ with probability $r$; from Table 1 we can see that $r=K /(K+G)$. If $d-l$ rejects this offer (which he does with probability $1-r$ ), then $P-L$ only gets $t-K$, since the case then goes to trial and court costs $(K)$ are deducted from the payoff $(t-K=T(L, l))$. Thus, $P-L$ 's expected utility is $K /(K+G)(t+G)+[G /(K+G)](t-k)$, which is what he would have gotten by initially demanding $S_{L}=(t)$.

Let us briefly look at another Case $\mathrm{A}$ example. We know from above that $d-h$ always rejects demand $t$. She will also reject $S_{\|}$with certainty. The case will go to trial; $d-h$ will pay $-(t-G)$, the 
In Cases $\mathrm{B}$ through $\mathrm{D}$, the probability that the defendant is type $l$ drops, in order, with $q_{l}$ being lowest in Case $\mathrm{D}$. In each of these of equilibrium cases, $P-L$ makes a weak demand, $t-G$, and $d$ always accepts it. In Cases $\mathrm{B}$ and $\mathrm{C}$, $P-H$ makes a strong demand, $t+G$. In Case $\mathrm{B}, d-l$ must reject $P-H$ 's demand with positive probability, and $P-L$ is indifferent between demanding $S_{L}$ and demanding $S_{H}$. In Case C, $d-l$ always accepts $P-H$ 's demand; $P-L$ strictly prefers $S_{L}$ to $S_{H}$. Finally, in Case $\mathrm{D}$, both types of plaintiff make weak demands. $P-H$ 's demand is sometimes rejected by $d-h$. This discourages $P-L$ from imitating $P-H$.

For fixed $K, G$, and $t, q_{l}$ determines which type of equilibrium exists. The equilibrium is unique provided $q_{l} \neq K /(G+K)$, and $q_{l} \neq[K /(K+2 G)]^{2}$. If $q_{l} \neq[K /(K+2 G)]^{2}$, then $P-L$ is indifferent between making a weak or a strong demand. Both the Case $\mathrm{A}$ and Case $\mathrm{B}$ (or a mixture) exist in this case. If $\left.q_{l}\right] K /(G+K)^{2}$, then $P-H$ is indifferent between making a weak or a strong demand. Both the Case $\mathrm{C}$ and Case $\mathrm{D}$ equilibria exist in this event.

The information in Table 1 can be used to evaluate the effects of mandatory discovery. The first thing to notice is that $d-h$ never gains from disclosure. For example, when $i=L$ and $j=h, d-h$ 's expected utility is $-t+G$ in each of the four cases A through D. Under mandatory disclosure, $d-h$ 's expected utility is again $-t+G$ and thus has done no better. Therefore, the no disclosure outcome is an equilibrium for the game in which disclosure is voluntary. Although $d-l$ may do better in a no disclosure equilibrium than in the mandatory disclosure equilibrium, $d-l$ benefits because $P$ believes that $j=h$ is possible. $d-l$ would not voluntarily choose to reveal that his information is bad. Notice that even if $P$ is skeptical in the sense that she believes $j=l$ unless $d$ makes a disclosure, it does not pay for $d-h$ to make a costly disclosure. This result follows because, regardless of the parameter values, $d-h$ does exactly as well as he expects to do should the dispute go to trial. Therefore, for the one-stage model, $d$ will not reveal $j$ unless disclosure is mandatory.

The next observation to make about Table 1 is that mandatory disclosure does not increase the ex ante probability of going to trial. This observation follows from simple algebra. Disclosure strictly reduces the probability of impasses in all but Case D. Providing $P$ with more information before she makes her demand leads to a higher probability of settlement. When $P$ does not know $j$, there is an incentive for her to make strong demands hoping that $j=l$; when $P$ knows $j, P-L$ settles all disputes. I defer a more complete discussion of the properties of equilibria until the end of Part V.

amount of the court award, and $P-L$ will receive $t-G-K$. Thus, $P-L$ cannot capture court costs here. 


\section{TABLE 1}

\section{Summary of Equilibrium OUtcomes}

(One-Stage Model)

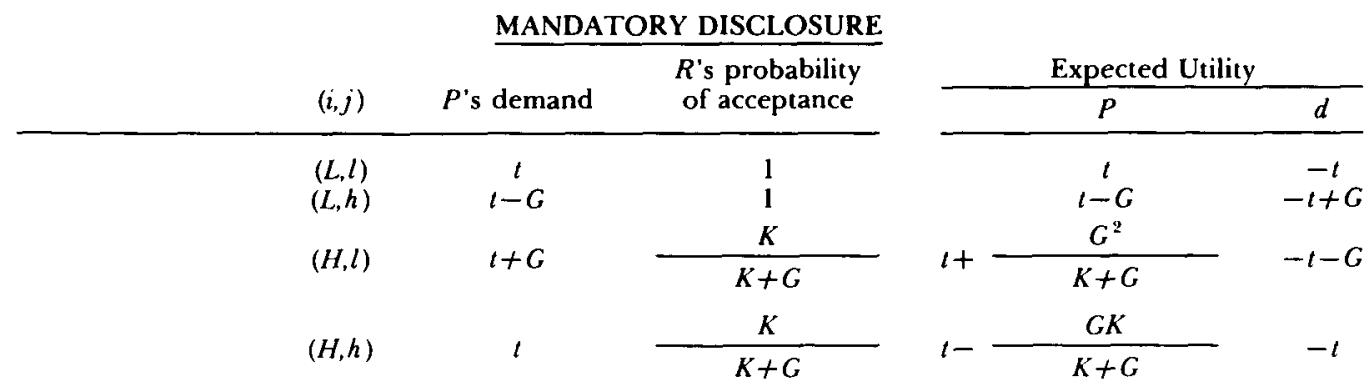

\section{NO DISCLOSURE}

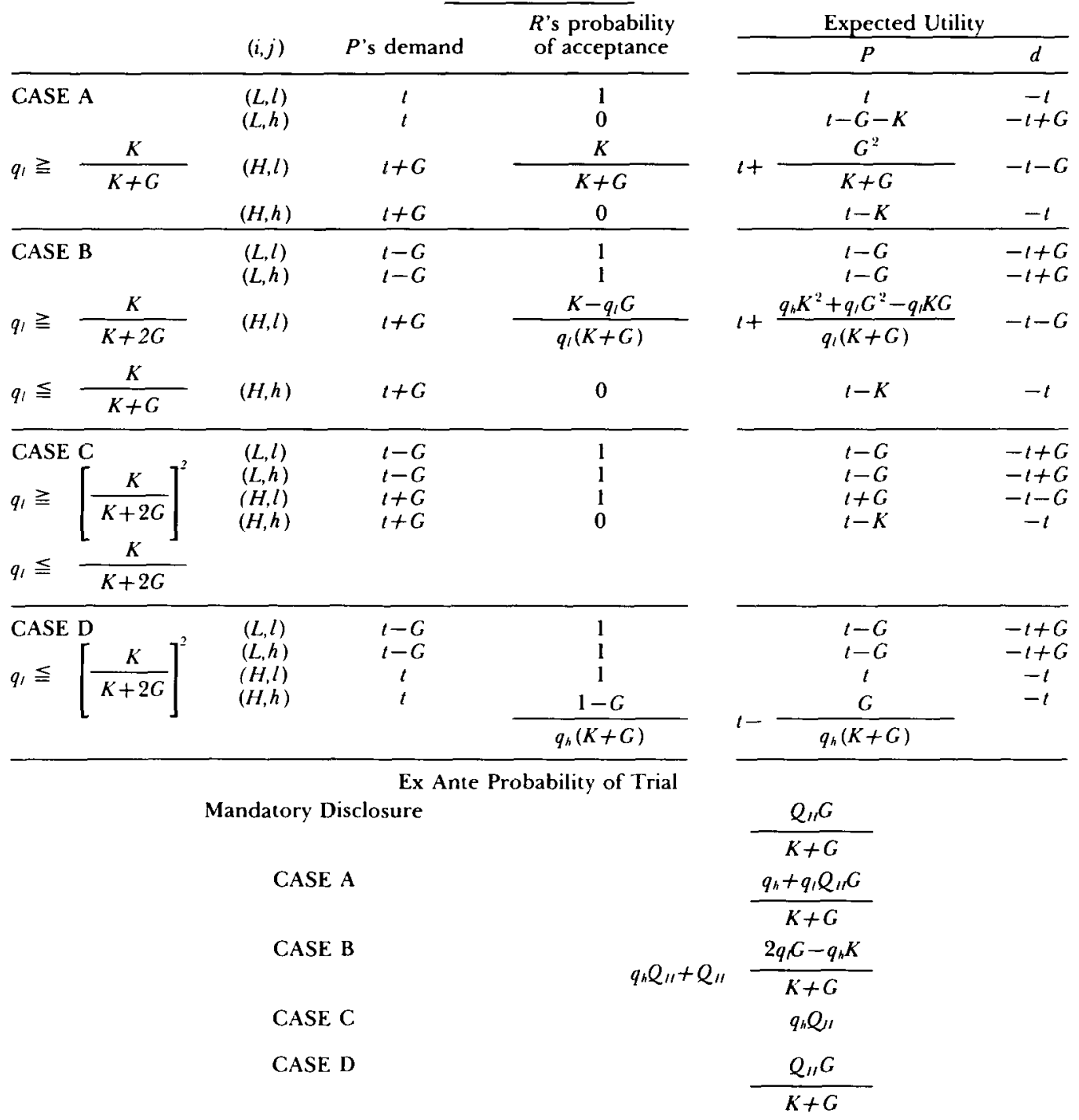




\section{IV \\ A One-Stage Model with Uninjured Plaintiffs}

In this Part, I discuss the discovery model of Part III. Here I assume that $T(L, j)<0$; that is, $P-L$ does not expect to win enough to make going to trial profitable. Under these circumstances, it is reasonable to assume that if $d$ rejects $P$ 's final offer, then $P$ drops the suit. Assume that the payoff to both $P$ and $d$ to a dropped suit is zero. Therefore, the payoffs to the players if $P$ demands $S$ are:

d

\begin{tabular}{l|ll}
\multicolumn{1}{l}{ P } & \multicolumn{1}{c}{ Accept } & \multicolumn{1}{c}{ Reject } \\
\hline $\mathrm{i}=\mathrm{L}$ & $\mathrm{S},-\mathrm{S}$ & 0,0 \\
$\mathrm{i}=\mathrm{H}$ & $\mathrm{S},-\mathrm{S}$ & $\mathrm{T}(\mathrm{H}, \mathrm{j}),-\mathrm{t}(\mathrm{H}, \mathrm{j})$
\end{tabular}

This model reduces to the model of the previous section, with $T(L, j)=t(L, j)=0$, since the weak case $(P-L)$ does not go to trial. The analysis of the previous section characterizes the unique D1-equilibrium outcome. In this equilibrium, $P-H$ always demands $t(\mathrm{H}, j)$ and $d$ rejects any non-negative demand. ${ }^{43}$ Equilibrium has these properties because if $d$ knows that $i=L$, then $P-L$ can never obtain a positive settlement in a separating equilibrium, ${ }^{44}$ whereas if $d$ accepts a demand $S>0$ with positive probability, $P-L$ can earn a positive expected payoff by demanding $S$ and then dropping the suit if $d$ rejects $S$. This conclusion does not depend on the magnitude of the court costs $(t(H, j)-T(H, j)$, nor on the prior probability that $d$ places on $i=L$ (provided that $Q_{L}>0$ ). Moreover, there exists a pooling equilibrium (in which all $P$ 's will make the same settlement demand) that seems to be very plausible when $Q_{L}$ is small. If $P$ is most often a $P-H$ type, $d$ will make payments to the few $P-L$ 's that litigate to avoid the danger of turning down $P-H$ 's offer and paying still more at trial. $P-H$ accepts the lower sure payoff, $Q_{H} t(H, j)$, since it is as good or better than what she can get in court, that is, $T(H, j) \leqq$ $Q_{H} t(H, j)$. So $P-i$ demands $Q_{H} t(H, j)$ for $i=L$ and $H$, and $d$ accepts this demand. Of course, to support this equilibrium, $d$ must reject with positive probability any demand $S>Q_{H} t(H, j)$. Therefore, he must believe that $P-L$ is at least as likely as $P-H$ to make a larger than expected demand. Ruling out beliefs of this kind leads to the outcome in which $P$ and $d$ never settle.

43. Nalebuff considers a model in which the defendant is fully informed, but the plaintiff lacks information about the defendant's liability and the probability that the defendant will be found liable in the event of a trial. He finds that a positive probability of a frivolous suit limits the possibility of pretrial settlements in equilibrium. Nalebuff, Credible Pretrial Negotiation, 18 Rand J. Econ. 198 (1987).

44. If all types of players pick the same strategy in all states, then the equilibrium is a pooling equilibrium. It is a separating equilibrium if different types make different demands. An example of a pooling equilibrium is one in which all litigants make the same settlement demand which is then accepted. An example of a separating equilibrium is one in which $P-H$ and $P-L$ demand different amounts. 
Several comments about this example are in order. First, the fact that the outcome does not depend on court costs is a result of the rules of the settlement game (that is, that $P$ makes the final demand), not the solution concept. Since $P$ makes the final demand, $d$ effectively must pay court costs whether or not he accepts the demand; $P$ 's demand will capture court costs since $P$ knows $d$ will have to pay these costs if the case goes to trial. Hence, the magnitude of these costs should not affect settlement probabilities. Second, the fact that the Dl outcome depends on the support of the prior on $P$ 's information $\left(q_{i}\right)$, but not on the values of $Q_{L}$ and $Q_{H}$, is characteristic of all separating equilibria in signaling models. Nevertheless, this property leads to a discontinuity: The limit of Dl outcomes as $Q_{L} \rightarrow 0$ (that is, as $Q_{L}$ approaches zero) is not an equilibrium of the complete information settlement game. (As $Q_{L} \rightarrow 0$, the pooling equilibrium described above does converge to the equilibrium of the complete information game.) This fact is disturbing from a theoretical perspective. However, the discovery process exists in a world of incomplete information. Thus, we can comfortably proceed with our discussion while keeping this problem in mind.

If you accept the refinement concept (D1) and its prediction for this model, there are still good reasons why you might expect different outcomes in situations in which $P-L$ does not expect to win if the suit goes to trial. In particular, there is a situation in which $P-L$ can benefit by committing herself to taking the disagreement to court. If $d$ knows that $P$ will not drop the suit, then it is in $d$ 's best interest to accept certain demands. Even an uninjured plaintiff is able to extract settlements from $d$ if the defendant's court costs exceed those of $P$.

In this section, a plaintiff who does not plan to continue her suit to trial cannot gain by filing a lawsuit. Thus, frivolous suits are not possible in this model. This result changes if $P$ is able to force $d$ into making costly disclosures should he fail to settle out of court.

I add this section to emphasize that the predictions of this model are very sensitive to the equilibrium concept and that the equilibrium concept leads to predictions that are counterintuitive.

The Two-Stage Model

This section treats the case in which both litigants are able to make settlement offers. The defendant makes the first offer. If $P$ rejects this offer, then she has the opportunity to make a demand prior to trial. I consider two possible rules governing disclosure of information: Either $d$ must disclose, at cost $c$, if $P$ rejects his settlement offer; or $d$ does not disclose his information. He cannot misrepresent the material he discloses; after disclosure, $P$ knows d's type.

The analysis of this Part parallels that of Part III. There is a cost to settlement only if there is a trial or if $d$ discloses; otherwise $P$ receives exactly what $d$ pays. Consequently, when discovery is not mandatory, there is no 
reason for $d$ to make a serious offer. The two-period model reduces to the one-period model with no disclosure. When discovery is mandatory, $d$ makes acceptable settlement offers with positive probability. The two-period mandatory discovery game is very similar to the one-period, no-discovery model discussed in Part III. In both of these games the litigant who moves first is uncertain about the opponent's type and pays a cost if the first offer is rejected. In the one-period, no-discovery model, $P$ moves first and must pay court costs if $d$ rejects her demand. However, the expected payoffs given a trial are known. In the two-stage, mandatory disclosure model, $d$ moves first and must pay $c$ if $P$ rejects his demand. However, if $P$ does reject $d$ 's demand, then the continuation of play reduces to a game studied in Part III.

\section{A. Mandatory Disclosure}

Table 2 summarizes the behavior on the path of the equilibrium outcomes that survive D1 when disclosure is mandatory. Except for rare parameter values, the outcome is unique.

I construct this equilibrium as I constructed the equilibria in Part III. First, I find the offer that $d-l$ would make if it were common knowledge that $j=l$. Next, I find $d-h$ 's best offer under the assumption that this offer signals to $P$ that $j=h$ and $d-l$ does not want to make $d-h$ 's offer. Except in one case, $d-l$ should be indifferent between making his equilibrium offer and imitating $d-h$. This is Case $\mathrm{C}$, which I describe below.

There are four kinds of equilibria. If $Q_{L}>c /(G+c)$ (that is, there is a high probability that $P$ is type $L$ ), then both types of defendant make offers that only $P-L$ might accept. $P-L$ accepts $d-l$ 's offer, $s_{l}$, with 100 percent probability but rejects $d-h$ 's offer, $s_{h}$, with positive probability in order to prevent $d-l$ from imitating $d-h$. As in Part III, it is straightforward to verify that, provided $d-l$ is indifferent between offering $s_{l}$ and $s_{h}$, any offer $s \in\left(s_{h} s_{l}\right)$ benefits $d-l$ more than $d-h$. Therefore, $P$ interprets this type of demand as signalling that $i=L$ and rejects it. In Case B, $d-l$ prefers to give in to both types of plaintiff, but $d-h$ makes a strong demand (low offer) that $P-H$ rejects with 100 percent probability. However, $d-l$ would prefer to make the offer $s_{h}$ if $P-L$ always accepted it. Therefore, $P-L$ rejects $s_{h}$ with positive probability and $d-l$ is indifferent between offers $s_{l}$ and $s_{h}$. Case $\mathrm{C}$ is qualitatively similar to Case $\mathrm{B}$. The only difference is that in Case $\mathrm{C}, d-l$ strictly prefers offering $s_{l}$ to $s_{h}$ even if $P-L$ always accepts $s_{h}$. Thus, $d-l$ is not indifferent to $d-h$ 's offer. As a consequence, $d-l$ can make an offer slightly greater than $s_{h}$, and $P-L$ will accept it with 100 percent probability. This does not disrupt the equilibrium because such an offer is less attractive to $d-l$ than $s_{h}$, which in turn is more attractive than $s_{l}$. In Case $\mathrm{D}$, both types of defendant make offers that appeal to $P-H . P-H$ rejects $d-h$ 's offer with positive probability in order to prevent $d-l$ from copying $d-h$ and thus support the equilibrium.

There is one feature of these equilibria that does not appear clearly in the one-stage equilibria. I must specify how $d$ responds when $P$ rejects his offer 
TABLE 2

Summary of Equilibrium Outcomes (Two-Stage Mandatory Disclosure Model)

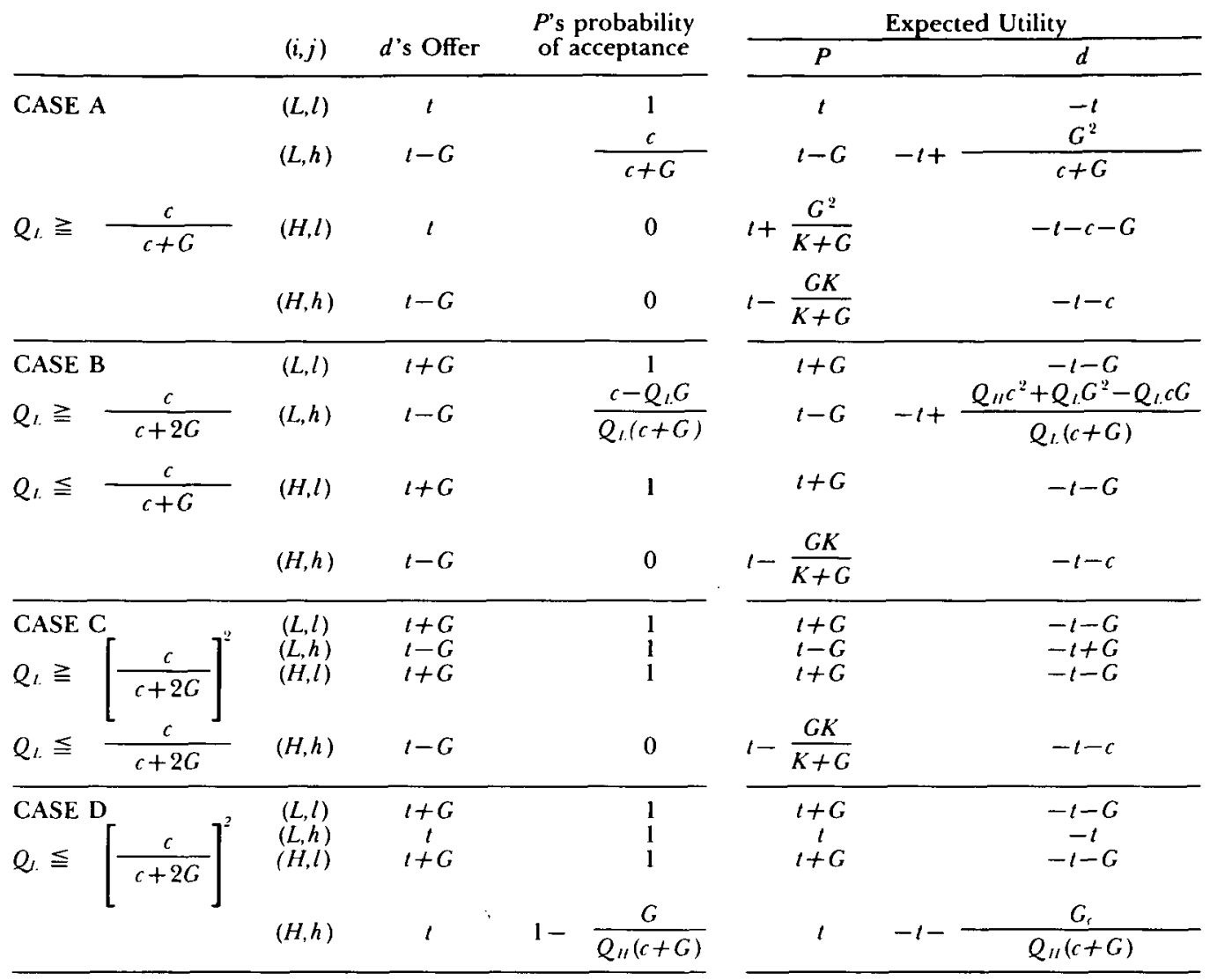

Ex Ante Disagreement Probabilities

CASE Probability of Disclosure
A$$
Q_{\prime \prime}+\frac{q_{h} Q_{t} G}{c+G}
$$
B$$
q_{11} Q_{11}+q_{1} Q_{t} \frac{2 Q_{1} \cdot G-Q_{n} c}{c+G}
$$
C
$q_{h} Q_{\prime \prime}$
D

Probability of Trial

$$
\begin{gathered}
\frac{Q_{1 \prime} G}{K+G} \\
\frac{q_{h} Q_{11} G}{K+G} \\
\frac{q_{h} Q_{1} G}{K+G}
\end{gathered}
$$

0

and counters with an unexpected demand. Equilibrium strategies have the property that demands slightly below $P-H$ 's demand are more likely to benefit $P-L$ than $P-H$. Thus, $d$ rejects them. In addition, in order to prevent $P-L$ from rejecting $d$ 's offer every time, it is necessary for $d$ to reject $P-H$ 's counter demand with positive probability. 
Perhaps the role of discovery and trial are puzzling in this model. After all, the defendants make separating offers (that convey information about their types) in equilibrium. Thus, even before $d$ reveals his private information, $P$ can infer $d$ 's type. Similarly, after $P$ makes her demand, the types of both litigants are common knowledge. If incomplete information is really the cause of bargaining impasses, but all the incomplete information disappears before impasses arise, why cannot we avoid costly discovery processes and trials? The answer is that it is precisely these costly procedures that make separating equilibria possible (that is, the threat of costly procedures makes it worthwhile to make serious offers that convey information to the other player). If $P-L$ could imitate $P-H$ without the risk of going to trial, she would do so. If $P$ always accepted an offer that ought to come from $d-h$ in equilibrium, it would pay for $d-l$ to make that offer as well. While this insight is not new and is indeed basic to all models with costly signaling, it is crucial to note that settlements occur only because of the presence of bargaining costs that litigants pay with positive probability in equilibrium. This point reappears in the discussion of the game in which no discovery takes place.

I have not explained why there are no equilibria satisfying D1 besides the outcomes presented in Table 2. The argument parallels the discussion in Part III. I summarize it briefly. Smaller offers typically signal that the defendant is type $h$. Hence, if $d-h$ makes an offer $s^{*}$ in equilibrium (which is accepted with a positive probability), then he can convince $P$ that $j=h$ by offering less than $s^{*}$. This means that in equilibrium, $d-h$ offers the amount that makes either $P-L$ or $P-H$ willing either to accept or reject given that $j=h$. Thus, $d-h$ makes one of two offers in equilibrium. How often $P$ accepts the offer depends on $d-l$. Specifically, if $P-i$ is indifferent between accepting or rejecting $d-h$ 's offer, and $P-i$ actually rejects $d-h$ 's offer with positive probability (to prevent $d-l$ from copying $d-h$ ), then $P$ must believe a slightly higher offer signals that $j=l$ with positive probability. Hence, if $P-i$ does reject $s_{h}$, then $d-l$ must be indifferent between offering $s_{l}$ and $s_{h}$. These arguments rule out outcomes that differ from those described in Table 2.

\section{B. No Disclosure}

When there is no discovery, neither litigant need pay if $P$ refuses to accept $d$ 's offer. For this reason, $d$ will not make a serious offer in any $\mathrm{D} 1$ outcome. There do exist sequential equilibria to the two-period, no-disclosure game in which $d$ makes a single offer (independent of $j$ ) and $P$ always accepts. However, these equilibria are equivalent to pooling equilibria in a one-period model in which $P$ makes a demand that does not depend on $i$, and $d$ accepts with 100 percent probability. This kind of equilibrium fails to satisfy D1 since a slightly lower offer by $d$ would benefit $d-h$ more than $d-l$ and would separate the two types; therefore, these offers would be accepted with 100 percent probability (since $P$ assumes the defendant has a strong case) in any equilibrium that survives criterion D1. 
The only Dl-equilibrium outcome under no disclosure in which $P$ accepts an offer with positive probability occurs when $d-h$ and $P-L$ agree to the same settlement that they agree to in the one-period, no-disclosure model. However, in this case, equilibrium outcomes are identical to those of Part III. Therefore, Table 1, Cases A-D describe the outcomes to the two-period, nodisclosure game.

Plainly, the conclusion that allowing $d$ to make an offer does not change the equilibrium depends critically on the assumption that $P$ can respond instantaneously (without cost) to any offer $d$ makes. However, the crucial assumption is that $d$ cannot respond to $P$ 's demand. While qualitative features of the equilibrium would change little if I imposed a small cost associated with rejecting an offer, the equilibrium could change considerably in a model in which the number of offers prior to trial is determined endogenously.

\section{Discussion}

As in the one-period version of the model, one cannot rely on voluntary disclosure to obtain relevant information if $c>0$. This result follows because disclosure is valuable only as a method of reducing the probability of trials. However, since $P$ makes the final offer prior to trial, she is able to extract all of the gains from an out-of-court settlement and thus $d$ has no incentive to disclose. Consequently, even if $P$ viewed $d$ 's failure to reveal that $j=h$ as proof that $j=l, d-h$ could simply reject $P$ 's settlement demand and do as well as he could in the no-disclosure equilibrium. Hence, the defendant would not pay to reveal his information to $P$. The extreme nature of this conclusion depends on $P$ 's ability to make the final offer and thereby extract the gains from discovery. However, it seems likely that the costs of disclosure exceed the private benefits of disclosure in more general specifications of the problem.

Grossman, Milgrom, and Milgrom and Roberts ${ }^{45}$ present models in which privately informed agents can make vague claims about their information, but cannot tell outright lies. They conclude that equilibrium behavior involves the uninformed agent responding skeptically to an opponent's disclosure and through this strategy, inferring all relevant information in equilibrium. My result shows that the Grossman-Milgrom-Roberts conclusion depends critically on the assumption that disclosure is costless. Since providing verifiable information is certainly costly in adversarial settings, it is not possible to rely on voluntary disclosure to reveal relevant information. ${ }^{46}$ If

45. Grossman, The Informational Role of Warranties and Private Disclosure about Product Quality, $24 \mathrm{~J}$. L. ECon. 461, 469 (1981); Milgrom, Good News and Bad News: Representation Theorems and Applications, 12 BelL J. ECon. 380, 388 (1981); Milgrom \& Roberts, Relying on the Information on Interested Parties, 17 RAND J. ECON. 18, 19 (1986).

46. In a different context, Farrell shows that the Grossman-Milgrom-Roberts result is sensitive to the assumption that disclosure costs are equal to zero. See Farrell, Voluntary Disclosure: Robustness of the Unraveling Result and Comments on its Importance, in Regulation and AnTrTRust 91,94 (R. Grieson ed. 1985). 
disclosure costs are common knowledge, then a third-party can pay a litigant's disclosure costs. However, in the typical case in which the disclosure costs are not common knowledge, this type of subsidy simply exchanges one incentive problem for another.

Shavell ${ }^{47}$ presents a model of the discovery process in which voluntary disclosure could lead to outcomes that are different from both no disclosure and full disclosure. In his model only the plaintiff has private information. First, the plaintiff decides whether to (costlessly) reveal this information. Second, the defendant makes a take-it-or-leave-it settlement offer. Finally, the dispute goes to trial if and only if the plaintiff rejects the offer. When disclosure is voluntary, Shavell finds equilibria in which only the most injured types of plaintiff reveal their information. Even though disclosure is free, it cannot be relied upon to lead to full revelation of information in this model.

The Grossman-Milgrom-Roberts result holds because if agents with different information all choose to reveal nothing, then it will be in the interest of the "best" to disclose rather than be pooled. ${ }^{48}$ However, in the model of Shavell, a defendant may make a settlement offer acceptable even to the type of plaintiff that has the best information in a pool. Otherwise, the plaintiff rejects the offer with positive probability and a costly trial follows.

In the model of this article, requiring mandatory discovery always reduces the probability of a trial. A simple computation demonstrates this result. The fraction $Q_{H} G /(K+G)$ represents both the maximum probability of a trial when disclosure is mandatory and the minimum probability of a trial when there is no disclosure. Similar computations show that both types of defendant prefer their expected payoff from the no-discovery equilibrium to the full disclosure equilibrium. $P$ prefers the discovery equilibrium to the nodiscovery equilibrium. These results are not surprising and do not appear to be sensitive to special features of the model.

Another general comparative-statics result describes the effect that changes in $G, K$, and $c$ have on equilibrium. The cost that $P$ pays if $d$ rejects her offer is $K$. As $K$ increases, the no-discovery equilibrium moves from Case A to $\mathrm{B}$ to $\mathrm{C}$ to $\mathrm{D}$; $P$ 's settlement demand becomes successively weaker; she will demand less since she loses more (high $K$ ) if the case goes to trial. Increasing $c$ induces $d$ to make larger settlement offers in the same way. Increasing $G$ causes litigants to make stronger settlement offers and increases the probability of trials. In this model, increasing the probability of trial turns out also to increase the equilibrium expected court costs. This result need not hold in general.49 People often argue that liberal discovery rules encourage frivolous suits. It is certainly possible for $P$ to extract a large settlement from $d$ when disclosure costs are high. Indeed, if there is a positive probability that $P$ is truly injured, then an uninjured plaintiff can extract a settlement from $d$ if $c$ is sufficiently large and disclosure is mandatory. This

47. Shavell, Sharing Information Prior to Settlement or Litigation, 20 Rand J. Econ. 184, 185 (1989).

48. Grossman, supra note 45; Milgrom \& Roberts, supra note 45, at 25.

49. See Samuelson, supra note 17. 
result holds even if an injured plaintiff drops her suit prior to trial; for sufficiently large $c, d$ would try to settle prior to discovery and $d$ might offer an uninjured plaintiff an amount large enough to induce a truly injured plaintiff to drop charges. ${ }^{50}$ The analysis of Part IV demonstrates that this type of action is not possible when discovery is not mandatory.

The model makes predictions about which types of disputes go to trial. When disclosure is mandatory, $P-L$ always settles prior to trial. Hence, the plaintiffs that do not settle always have strong cases. Therefore, the disputes that go to trial will be settled in favor of the plaintiff a disproportionate fraction of the time. The extent of this bias depends upon parameter values; $d-l$ tends to settle disputes out of court as well. Further, the direction of the bias depends upon two modeling assumptions. First, since discovery is onesided, the defendant cannot discover directly that the plaintiff's case is weak. Second, the arbitrary restriction that the plaintiff makes the final settlement offer influences the sample of disputes that are not settled. Consequently, I make no claims about the relationship between the results of trials and the underlying distribution type of disputes that are settled. Priest and Klein ${ }^{51}$ emphasize the importance of determining the relationship between judicial decisions, which are observable, and settlement outcomes. They present a model in which trial judgments will be for the plaintiff 50 percent of the time independent of the rules for allocating costs. Their results indicate that changing disclosure rules could influence the outcomes at trial.

\section{VI \\ Limitations and Apologies}

My analysis suffers from the simplicity of my model and the particular form of the settlement game that I analyze. The remainder of this Part discusses the limitations of my approach and potential improvements.

First, my model of the discovery process is too simple to incorporate essential characteristics of information transmission prior to trial. Because of the way I modeled information, the difficult issue of how much effort the plaintiff should spend questioning the defendant does not arise. In my model, discovery imposes no direct costs on the plaintiff and always allows $P$ to acquire complete information. A more realistic model would require the plaintiff to grope about in an attempt to discover the issues about which the defendant has valuable information and would model the way in which an informed plaintiff prepares a response to potentially damaging information.

Second, in my paper discovery is a one-sided process. I made this assumption in order to avoid complications. However, since there is twosided uncertainty in this model, it is natural to ask what would happen if the plaintiff could also be forced to disclose information. The answer is sensitive

50. Rosenberg and Shavell present a model that demonstrates the possibility of frivolous suits. See Rosenberg \& Shavell, A Model of the Nuisance Suit, 5 INT'L Rev. L. Econ. 3 (1985).

51. Priest \& Klein, The Selection of Disputes for Litigation, 13 J. Legal STud. 1 (1984). 
to the way I model the sequence of moves. However, potential litigants settle all disputes in a model in which full disclosure is mandatory, players move sequentially, and trial is costly. The discovery process reveals all information that could lead to disagreement. This conclusion naturally does not hold if disclosure is partial nor need it hold if the bargaining process involves simultaneous moves and hence the possibility of coordination failures.

Third, a standard argument in favor of liberal discovery rules is that the discovery process eliminates trial by surprise, whereby one party can gain an unwarranted advantage at trial by presenting arguments that the other side was unaware of and cannot respond to. Analysis of this effect is beyond the scope of my model.

Fourth, liberal discovery rules are said to allow for fairer settlements. The intuition behind the assertion that more information leads to better decisions is straightforward, but not completely persuasive. First, the ability to impose discovery costs on the defendant may cause $d$ to settle prior to discovery. There is no reason to believe that these settlements are fair. Second, the decision-theoretic intuition that more information leads to better decisions does not hold in strategic environments. Consequently, disclosure of information may not improve the quality of settlements. My model has nothing to say about this issue because I provide no measure of welfare. In order to build a normative theory of the settlement and litigation process, a model would necessarily regard a third party, identified perhaps as a judge, as a strategic player able to design rules in order to achieve an objective. At a theoretical level, it is clear that the judge should be interested in both reducing the costs of the litigation process and guaranteeing that the process leads to fair outcomes. As a practical matter, it is more difficult to find an objective function that adequately incorporates the trade-offs involved in balancing these two goals. The absence of an adequate welfare measure puts the theorist in a difficult position. It becomes easy to judge the judicial process on quantities like the probability of settlement, which can be increased simply by increasing court costs but which ignores the nature of settlements made.

Fifth, disclosure of information may impose costs or benefits because third parties obtain access to information disclosed during the settlement process. Also, an extended discovery process may benefit one litigant by postponing the date of settlement. I ignore these effects.

I have not presented any results about how rules that govern the allocation of court costs affect settlements. It would be easy to reinterpret the model to allow this type of analysis. However, I do not believe that this analysis would be useful. In a model in which litigants alternate offers, the litigant who makes the offer immediately prior to trial has the ability to demand that the other litigant pay court costs as part of the settlement. Therefore, this type of model predicts that settlement probabilities do not depend on the rule governing the allocation of costs and only act as a transfer from one litigant to 
the other. ${ }^{52}$ Useful results might come from a model in which endogenous variables determine the number of offers prior to trial. It may be possible to build such a model if litigants discount future payments and the plaintiff has a right to demand a trial at any stage of the pretrial bargaining process. It may be rational for a plaintiff to demand a trial if the cost of waiting for an appropriate settlement offer exceeds her court costs.

\section{VII}

\section{ConClusion}

The model of this article makes the point that bargaining costs, whether they are delays, costs of trials, or costs of disclosing information, are essential aspects of any litigation problem in which parties have access to private information relevant to the dispute. Increasing court costs lowers the plaintiff's demand (since the plaintiff essentially pays court costs if the case goes to trial). An increasing gap between trial payoffs to seriously and mildly injured plaintiffs leads to stronger offers by both the plaintiff and the defendant, and increases the probability of a trial.

The article also applies techniques that select a unique equilibrium outcome for a simple two-stage model of the litigation process. The analysis demonstrates that if disclosure is costly, then the defendant will not voluntarily disclose information; that mandatory discovery reduces the probability of trials, benefits plaintiffs, and harms defendants. Under mandatory disclosure, increasing disclosure costs induces the defendant to make larger offers. The assertions about the effects of mandatory disclosure are, for the most part, well known. Brazil describes these properties and others. ${ }^{53}$ The analysis also suggests that the litigation process typically provides a biased sample of disputes for trial. The extent of bias is dependent on the parameter values, the process of discovery, and who makes the final offer.

52. See Reinganum \& Wilde, supra note 3.

53. Brazil, The Adversary Character of Civil Discovery: A Critique and Proposal for Change, 31 VAND. L. REv. 1295 (1978). Brazil provides an extensive critical review of the practical implications of discovery rules. He describes the benefits of mandatory discovery under ideal circumstances: that it leads to an increased chance of learning the truth about a dispute; that it limits the potential for trial by surprise; that it could increase the probability of settlement of disputes; and that it could "shorten and streamline" the judicial process. Id. at 1300-03. These effects appear clearly in the results of my model. Brazil's review emphasizes that these effects are unlikely to take place in practice, where there are no rewards to attorneys for conscientious adherence to discovery rules, id. at 1313, and limited sanctions against those who fail to follow them, id. at 1340-43. The article also points out the potential, which appears in my model, to use the discovery process to impose costs on adversaries. Id. at 1319-22. 


\section{APPENDix}

The appendix sketches a proof that explains why the outcome described in Part III is the only one that satisfies the D1 criterion. First, I describe the criterion as it applies to the model in Part III.A.

Fix a sequential equilibrium in which $u_{i}^{*}$ is $P-i$ 's equilibrium expected utility. Let $S$ be a demand that $P$ does not make in equilibrium and let

I require that if

$$
B_{i}(S)=\left\{r: r S+(1-r) T(i, j) \geqslant u_{i}^{*}\right\} \text {. }
$$

$$
B_{i}(S) \subseteq B_{1-i}(S) \text { and } B_{i}(S) \neq B_{I-i}(S) \text {, then } \mu(i \mid S)=0 \text {. }
$$

D1 guarantees that if $P-H$ would gain (relative to her expected utility $u_{i}^{*}$ ) by demanding $S$ whenever $P-L$ would gain, then the defendant should interpret this demand as a signal that $i=H$.

I now show that the sequential equilibrium described in Part III satisfies D1 and that it is (essentially) the unique equilibrium outcome that does so. First, I show that the beliefs that support the equilibrium satisfy (D1). Since there is a unique best response to a demand $S k[t(L, j), t(H, j)]$ and this response attracts neither type of plaintiff, it suffices to show that if $S \in(t(L, j)$, $t(H, j)$ and $d$ accepts $S$ with probability $r$, then the set of $r$ for which $P-L$ prefers $S$ to the equilibrium demand strictly contains the set of $r$ for which $P-H$ prefers $S$ to the equilibrium demand. $P-L$ weakly prefers to defect from the equilibrium if and only if

$$
r S+(1-r) T(L, j) \geqslant t(L, j) \text { or } r \geqslant r_{l}=[T(L, j)-T(L, j)] /[S-T(L, j)]
$$

and $P-H$ weakly prefers to defect if and only if

$$
\begin{aligned}
& r S+(1-r) T(H, j) \geqslant r^{*} t(H, j)+\left(1-r^{*}\right) T(H, j) \\
&=t(L, j)+\left(1-r^{*}\right)(T(H, j)-T(L, j)) \text { or } \\
& r \geqslant r_{h}=\left[t(L, j)-T(L, j)-r^{*}(T(H, j)-T(L, j))\right] /[S-T(L, j)-(T(H, j)-T(L, j))] .
\end{aligned}
$$

It is straightforward to check that $r_{h}>r_{l}$; thus, $P-L$ prefers to defect whenever $P-H$ prefers to defect. It follows that the strategies and beliefs of Proposition 1 constitute a Dl equilibrium.

Two observations imply that there is no other outcome that survives D1.

(a) If $P-H$ makes a demand $S *<t(H, j)$ with positive probability in a sequential equilibrium, then any demand $S \epsilon\left(S^{*}, t(H, j)\right)$ benefits $P-H$ more than $P-L$.

(b) For any sequential equilibrium in which $P-L$ strictly prefers her equilibrium payoff to the expected utility that she would receive from a demand $S^{*}$ that $P-H$ makes with positive probability there exists an $a>0$ such that any demand $S \in\left(S^{*}-a, S^{*}\right)$ benefits $P-H$ more than $P-L$.

These observations follow from simple algebra. Fact (a) states that an unexpectedly high demand benefits $P-H$ whenever it benefits $P-L$. The restriction $S^{*}<t(H, j)$ is necessary because $d$ rejects any demand that exceeds $t(H, j)$. Fact (b) states that $P-H$ benefits more than $P-L$ from a demand slightly less than $P-H$ 's equilibrium demand provided that $P-L$ 's equilibrium payoff dominates the payoff $P-L$ would receive from imitating $P-H$. 
Fact (a) implies that $P-H$ must always demand $t(H, j)$ if beliefs satisfy Dl. Otherwise, $P-H$ could gain by making a larger demand, which by Fact (a) and (D1) would be accepted with 100 percent probability. Fact (b) implies that $P-L$ must be indifferent between demanding $t(H, j)$ and her equilibrium demand. To see this, observe that $d$ must reject $t(H, j)$ with positive probability, for if $d$ always accepted $t(H, j)$, then $P-L$ would always demand $t(H, j)$, but in this case $d$ 's best response is to reject the demand. Consequently, if $P-L$ strictly prefers to make some demand other than $t(H, j)$, $P-H$ could demand slightly less than $t(H, j)$, thereby signaling her type to $d$. Therefore, $d$ would accept this demand with 100 percent probability. Hence, in any outcome that survives Dl, $P-H$ demands $t(H, j), P-L$ makes some other demand $S$, but $P-L$ is indifferent between $S$ and $t(H, j)$. Since $S$ reveals to $d$ that $i=L$, it must be that $S=t(L, j)$. Since $t(L, j)>T(L, j)$ and $d$ rejects $t(H, j)$ with 100 percent probability if $P-L$ makes this demand with positive probability, it must be that $P-L$ demands $t(L, j)$ with 100 percent probability. 
